Revista Brasileira de Farmacognosia Brazilian Journal of Pharmacognosy 21(4): 704-709, Jul./Aug. 2011

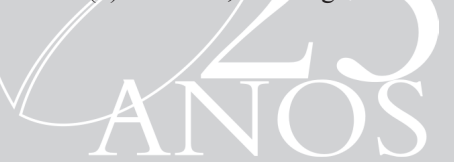

Article

Received 25 Aug 2010

Accepted 3 Jan 2011

Available online 20 May 2011

Keywords:

adriamycin

Bombax ceiba

cardiovascular disease

catalase

vitamin $\mathrm{E}$

ISSN 0102-695X

doi: $10.1590 / \mathrm{S} 0102-695 \mathrm{X} 2011005000090$

\section{Cardioprotective effect of Bombax ceiba flowers against acute adriamycin-induced myocardial infarction in rats}

\author{
Sita Sharan Patel, ${ }^{, 1}$ Neelesh Kumar Verma, ${ }^{1}$ Beauty Rathore, ${ }^{2}$ \\ Govind Nayak, ${ }^{2}$ Akhlesh Kumar Singhai, ${ }^{2}$ Priya Singh ${ }^{3}$ \\ ${ }^{I}$ Cardiovascular Research Division, Himalayan Pharmacy Institute, India, \\ ${ }^{2}$ Division of Pharmacology, Lakshmi Narain College of Pharmacy, India, \\ ${ }^{3}$ Department of Phytochemistry \& Pharmacognosy, V.N.S. Institute of \\ Pharmacy, India.
}

\begin{abstract}
The present study was designed to evaluate the cardioprotective potential of aqueous flower extract of Bombax ceiba L., Malvaceae (BC), on the basis of biochemical and histopathological parameters in Adriamycin (Adr) induced myocardial infarction in rats and to compare with vitamin $\mathrm{E}$, a known cardioprotective antioxidant. Male Wister rats were used as in vivo model for the study. BC was administered orally to Wister rats at different doses $(150 \mathrm{mg} / \mathrm{kg}$, $300 \mathrm{mg} / \mathrm{kg}$ and $450 \mathrm{mg} / \mathrm{kg}$, b.w.) for six days/week for four weeks. Thereafter, all the groups except saline were administered $\mathrm{Adr}(20 \mathrm{mg} / \mathrm{kg}$, i.p. $)$. There was a significant decrease in myocardial superoxide dismutase, catalase and reduced glutathione in animals treated with Adr. Concurrently marked increase in extent of lipid peroxidation was reported. Co-treatment of $\mathrm{BC} /$ vitamin $\mathrm{E}$ and Adr resulted in an increase in the cardiac antioxidant enzymes and reduction in lipid peroxidation as compared to Adr-treated animals. Adr showed significant decrease $(p<0.001)$ in the level of cardiac marker enzymes [Lactate dehydrogenase (LDH) and Serum glutamic oxaloacetic transaminase (SGOT)] in heart homogenate with corresponding increase in their level in serum. In $\mathrm{BC} /$ vitamin $\mathrm{E}$ treated groups significant increase $(p<0.001)$ of LDH in heart homogenate and decrease of SGOT and LDH in serum were observed. Microscopic studies in Adr-treated animals revealed mitochondrial swelling, leukocyte infiltration, lipid inclusions and myofibrillar loss whereas the pre-treatment with $\mathrm{BC} /$ vitamin $\mathrm{E}$ led to a lesser degree of Adr-induced histological alterations. These findings suggest that aqueous flower extract of $\mathrm{BC}$ has protective effect against Adr-induced cardiotoxicity and may have potential as a cardioprotective agent.
\end{abstract}

\section{Introduction}

Cardiovascular disease (CVD) is now the most common cause of death worldwide. Before 1900, infectious diseases and malnutrition were the most common cause of death throughout the world, and CVD was responsible for less than $10 \%$ of all deaths. Today CVD accounts for $\sim 30 \%$ of death worldwide, including nearly $40 \%$ in high-income countries and about $28 \%$ in low- and middle-income countries (Gaziano \& Gaziano, 2008). Myocardial infarction is the acute condition of necrosis of the myocardium that occurs as a result of imbalance between coronary blood supply and myocardial demand. It is well recognized that ischemic tissue generates oxygen-derived free radicals and other reactive species which bring about oxidative damage of membrane lipids, proteins, carbohydrates and DNA, leading to qualitative and quantitative alterations of the myocardium (Panda \& Naik, 2008). Adriamycin (Adr), anthracycline antibiotics commonly used against human cancers has well known dose dependent cytotoxic effect. Although the mechanism underlying the severe cytotoxicity of Adr and other anthracyclines are not fully understood, there is an evidence that drug toxicity may ensue through free radical formation (Sinha \& Politi, 1990) and subsequent redox cycle with $\mathrm{O}_{2}$ resulting in the generation of reactive oxygen species such as superoxide anion, hydroxyl radicals and hydrogen peroxide. Tissue with less developed antioxidant defences such as heart is particularly susceptible to injury by Adr-induced oxygen radicals (Olson \& Mushlin, 1990). These cardiotoxic effects result from overwhelming production of reactive oxygen species (ROS) and concomitant decrease in the levels of antioxidants like superoxide dismutase (SOD), 
catalase (CAT) and reduced glutathione (GSH).

A large proportion of the Indian population for their physical and psychological health needs depend on traditional system of medicine. Medicinal plants have become the focus of intense study in terms of conservation as to whether their traditional uses are supported by actual pharmacological effects or merely based on folklore. Herbal medicines are free from side effects and less costly when compared to synthetic drugs. Bombax ceiba L., Malvaceae (BC), is an important medicinal plant of tropical and subtropical India. Its medicinal usage has been reported in the traditional systems of medicine such as Ayurveda, Siddha and Unani. Bombax ceiba described as a cotton tree and it is used extensively for treatment of some diseases like inflammation (Buckingham, 1992), algesia, hepatotoxicity (Saleem et al., 2003) and CVD i.e. hypertension, as well as well known for anti-angiogenic and in addition, $\mathrm{BC}$ is also known to be endowed with potent free-radical scavenging activity (Vieira et al., 2009). The effect of BC on Adr-induced cardiotoxicity is still unclear; hence the present work includes the cardioprotective activity of aqueous flower extract of BC against Adr-induced myocardial infarction in rats.

\section{Materials and Methods}

\section{Plant material}

The flowers of Bombax ceiba L., Malvaceae, were collected in the month of October from Eastern part of India, (Sikkim Himalayas) Majhitar, East Sikkim, India. The Herbarium specimen (No. 167) of plant was deposited in the Department of Pharmacognosy and it was identified by Dr. J. P. Mohanty, the Head Department of Pharmacognosy, Himalayan Pharmacy Institute, East Sikkim.

\section{Extraction}

After collection and identification the flowers were dried in shade and powdered (no. 60 mesh) and 100 $\mathrm{g}$ of the dried powder was soxhlet extracted successively with petroleum ether, chloroform, methanol and water. The weight of aqueous extract after drying was calculated as $4.77 \mathrm{~g}$.

\section{Experimental animals}

Adult albino rats (Wister strain, 200-250 g) were used. They were housed in standard environmental conditions and fed with rodent diet and water ad libitum. All animal experiments were carried out in accordance with the guidelines of Committee for the Purpose of Control and Supervision on Experiments on Animals (CPCSEA, 2003). The institutional animal ethical committee has given approval for conducting animal experiments (HPI/08/60/IAEC/0043).

\section{Cardioprotective activity}

To study the effect of aqueous extract of BC against Adr-induced cardiotoxicity, six groups of seven animals in each were taken and treated as follows, maximum tolerated dose of $\mathrm{BC}$ were administered:

Group I: Normal saline $(0.75 \mathrm{ml} /$ animal $)$, orally 6 days/ week for 4 weeks.

Group II: Saline (0.75 ml/animal) + Adr (20 mg/kg), single i.p. injection after 4 weeks.

Group III: BC (150 mg/kg), orally for 4 weeks + Adr single i.p. injection after 4 weeks.

Group IV: BC (300 mg/kg), orally for 4 weeks + Adr single i.p. injection after 4 weeks.

Group V: BC $(450 \mathrm{mg} / \mathrm{kg})$, orally for 4 weeks $+\mathrm{Adr}$ single i.p. injection after 4 weeks.

Group VI: Vitamin E (100 mg/kg), orally for 4 weeks + Adr single i.p. injection after 4 weeks.

The animals were sacrificed after $48 \mathrm{~h}$ of Adr administration under pentobarbital sodium (50 $\mathrm{mg} /$ $\mathrm{kg}$, i.p.) anesthesia and hearts were excised out for the estimation of biochemical parameters and histological studies.

\section{Biochemical assays}

Frozen tissue sample of the rat hearts were weighed and homogenized (Homogenizer REMI RQM122, Remi Instrument, India) (1:10, w/v) in $100 \mathrm{mmol} / \mathrm{L}$ phosphate buffer ( $\mathrm{pH} 7.4$ ) containing $0.05 \%$ sodium azide in an ice bath. The homogenate was centrifuged at $5000 \mathrm{rpm}$ for $10 \mathrm{~min}$. The supernatant was frozen at -78 ${ }^{\circ} \mathrm{C}$ in aliquots until used for biochemical assays.

\section{Protein estimation}

The levels of total proteins were determined in heart homogenates of experimental animals by using the Bradford (1976) method.

\section{Lipid peroxidation}

Thiobarbituric acid reactive substances (TBARS) levels in the heart homogenates and serum were determined by modified method of Okhawa et al., (1979). Heart tissues were homogenized in 10\% trichloroacetic acid (TCA) buffer in ice. $0.2 \mathrm{~mL}$ of homogenate was pipetted into a test tube, followed by the addition of $0.2 \mathrm{~mL}$ of $8.1 \%$ sodium dodecyl sulphate (SDS), $1.5 \mathrm{~mL}$ of $20 \%$ acetic acid $(\mathrm{pH} \mathrm{3.5)}$ and $1.5 \mathrm{~mL}$ of $0.8 \%$ thiobarbituric acid (TBA). Tubes were boiled at $95^{\circ} \mathrm{C}$ for $60 \mathrm{~min}$ and then cooled. $1.0 \mathrm{~mL}$ of double- 
distilled water and $5.0 \mathrm{~mL}$ of n-butanol:pyridine (15:1, $\mathrm{v} / \mathrm{v})$ mixture were added to the tubes and centrifuged at $5000 \mathrm{rpm}$ for $10 \mathrm{~min}$. The absorbance of organic layer was measured at $540 \mathrm{~nm}$. Malonyldialdehyde (MDA), an end product of lipid peroxidation forms pink color adducts with TBARS. The extent of lipid peroxidation was expressed as $\mu \mathrm{M}$ of MDA/g heart tissue.

\section{Glutathione estimation}

Myocardial GSH was estimated according to the modified method of Ellman (1959). The heart tissues were homogenized with $10 \%$ TCA buffer and centrifuged at $3000 \mathrm{rpm}$ for $10 \mathrm{~min}$ at $4{ }^{\circ} \mathrm{C}$. The reaction mixture contained $0.1 \mathrm{~mL}$ of supernatant, $2.0 \mathrm{~mL}$ of $0.3 \mathrm{M}$ phosphate buffer ( $\mathrm{pH} 8.4$ ) $0.4 \mathrm{~mL}$ of double-distilled water and $0.5 \mathrm{~mL}$ of DTNB [5,5-dithiobis(2-nitrobenzoic acid)]. The reaction mixture was incubated for $10 \mathrm{~min}$ and the absorbance was measured at $412 \mathrm{~nm}$ within 15 $\mathrm{min}$. The concentration of GSH was expressed as $\mu \mathrm{g} / \mathrm{g}$ of heart tissue.

\section{Antioxidant enzyme assays in heart homogenates}

SOD levels in the myocardial tissue of rats were determined according to the modified method of Kakkar et al. (1984). Briefly heart tissues were homogenized in $0.25 \mathrm{M}$ Tris sucrose buffer $\mathrm{pH} 7.4$ and centrifuged at $10,000 \mathrm{rpm}$ for $15 \mathrm{~min}$ at $4{ }^{\circ} \mathrm{C}$. Supernatant $(600 \mu \mathrm{L})$ was added to the solution containing $1.2 \mathrm{~mL}$ of sodium pyrophosphate buffer $(0.052 \mathrm{M}, \mathrm{pH} 8.3), 0.1 \mathrm{~mL}$ of phenazine methosulphate solution $(186 \mu \mathrm{M})$ and $0.3 \mathrm{~mL}$ of nitro blue tetrazolium solution $(300 \mu \mathrm{M})$. Reaction was initiated by the addition of $0.2 \mathrm{~mL}$ of nicotinamide adenine dinucleotide-reduced disodium salt (NADH) solution $(780 \mu \mathrm{M})$. This reaction mixture was incubated for $90 \mathrm{~s}$ at room temperature and then stopped by the addition of $1 \mathrm{~mL}$ glacial acetic acid. Absorbance of reaction mixture was read spectrophotometrically at 560 $\mathrm{nm}$. SOD activity was expressed as U/mg protein.

Levels of CAT were estimated by the modified method of Aebi (1984). Hearts were homogenized at 4 ${ }^{\circ} \mathrm{C}$ in $50 \mathrm{mM}$ potassium phosphate buffer $(\mathrm{pH} 7.4)$ and centrifuged at $5000 \mathrm{rpm}$ for $10 \mathrm{~min}$. Ethanol equal to $0.01 \mathrm{~mL} / \mathrm{mL}$ of supernatant was added and incubated for $30 \mathrm{~min}$ in ice. Triton 100X was added to the final concentration of $1 \%$. Supernatant $(50 \mu \mathrm{L})$ was added to a cuvette containing $1.95 \mathrm{~mL}$ of $50 \mathrm{mM}$ phosphate buffer (pH 7.0). Then $1.0 \mathrm{~mL}$ of $30 \mathrm{mM}$ hydrogen peroxide was added and rate of decomposition of hydrogen peroxide was measured spectrophotometrically at $240 \mathrm{~nm}$. CAT activity was expressed as $\mathrm{U} / \mathrm{mg}$ protein.

Glutathione peroxidase (GSH-Px) estimation was carried out using the method of Rotruck et al. (1973), which makes use of the following reaction:

$$
\mathrm{H}_{2} \mathrm{O}_{2}+2 \mathrm{GSH} \rightarrow 2 \mathrm{H}_{2} \mathrm{O}+\mathrm{GSSG} \text { (oxidized glutathione) }
$$

GSH-Px in the tissue homogenate oxidizes glutathione and simultaneously, $\mathrm{H}_{2} \mathrm{O}_{2}$ is reduced to water. This reaction is arrested at $10 \mathrm{~min}$ using trichloroacetic acid and the remaining glutathione is reacted with DTNB solution to result in a colored compound, which is measured spectrophotometrically at $420 \mathrm{~nm}$.

\section{Cardiac biomarkers}

Lactate dehydrogenase (LDH) and Serum glutamic oxaloacetic transaminase (SGOT) activities in heart homogenate and serum were assayed by using Star 21 plus Biochemistry Auto Analyser (Cuesta Care Inc., Atascadero, USA).

\section{Histopathological examination}

The heart tissues (one from each) obtained from all experimental groups were washed immediately with saline and then fixed in $10 \%$ buffered neutral formalin solution. After fixation, the heart tissues were processed embedding in paraffin. Then, the tissues were sectioned and stained with haematoxylin and eosin ( $\mathrm{H} \mathrm{\&} \mathrm{E)} \mathrm{and}$ examined under high power microscope (x 400) and photomicrographs were taken.

\section{Statistical analysis}

The results were subjected to one way analysis of variance (ANOVA) followed by Bonferroni test $p<0.05$ were considered significant.

\section{Results and discussion}

The current study entails the cardioprotective potential of the aqueous flower extract of $\mathrm{BC}$ against acute Adr-induced cardiotoxicity for the first time. $\mathrm{BC}$ is a plant, well known for its cardioprotective properties in the traditional Indian system of medicine. In the present study cardioprotective effect of chronic oral administration of $\mathrm{BC}$ against Adr-induced acute cardiotoxicity were evaluated in male Wister rats. The major chemical constituents present in the aqueous extract of $\mathrm{BC}$ (tannins, flavonoids and glycosides) may be responsible for the potent antioxidant activities (Vieira et al., 2009).

The existing experimental evidences suggest that Adr-induced oxidative stress is due to the generation of free radicals in the heart tissue (Hardina et al., 2000; Naidu et al., 2002). The principle ROS generated are superoxide radicals and hydroxyl radicals, which have the potential to cause damage to various intracellular components. Cardiac muscle is particularly susceptible 
to free-radical injury, because it contains low levels of free-radical detoxifying enzymes/molecules like SOD, GSH and CAT (Takacs et al., 1992). Furthermore, Adr also has high affinity for the phospholipid component of mitochondrial membrane in cardiac myocyte, leading to accumulation of Adr in the heart tissue (Takacs et al., 1992). It was observed that $20 \mathrm{mg} / \mathrm{kg}$ (Singh et al., 2008) dose of Adr-induced moderate lesions in the myocardium and significantly altered various biochemical parameters resulting myocardial infarction. Therefore, the cardioprotective activity of $\mathrm{BC}$ was evaluated against this dose.

Myocardial lipid peroxidation was significantly increased $(p<0.001)$ in Adr-treated animals as compared to normal animals. Pre-treatment with BC $(300 \mathrm{mg} /$ $\mathrm{kg}$ and $450 \mathrm{mg} / \mathrm{kg}$ ) and vitamin $\mathrm{E}$ showed significant $(p<0.001)$ reduction of lipid peroxidation as compared to GII (Table 1). Adr-induced myocardial lesions have been well documented in patients as well as in experimental animals (Ytrehus \& Hegstad, 1991; Lenaz \& Page, 1976; Doroshow, 1991). Studies have shown the Adr cardiotoxicity to proceed via production of free radicals. Lipid peroxidation has been identified as one of the basic deteriorative reactions in cellular mechanisms during free radicals induced myocardial injury. The increased levels of malondialdehyde (MDA) indicate excessive formation of free radicals by Adr and activation of the lipid peroxidative process, resulting in irreversible damage to heart in animals subjected to Adr stress. BC treatment significantly decreased the MDA levels by preventing formation of lipid peroxides from fatty acids.

Myocardial GSH levels were significantly reduced $(p<0.001)$ in Adr-treated animals as compared to untreated animals. Pre-treatment with BC showed significant increase $(p<0.001)$ in GSH levels at the doses of $300 \mathrm{mg} / \mathrm{kg}$ and $450 \mathrm{mg} / \mathrm{kg}$ as compared to Adr treated group. Treatment of animals with dose of $150 \mathrm{mg} / \mathrm{kg}$ of $\mathrm{BC}$ led to insignificant alteration in the levels of $\mathrm{GSH}$ (Table 1).

Reduced glutathione is one of the most abundant non-enzymatic antioxidant bio-molecule present in the body (Meister, 1984). Together with GSH-Px, glutathione reductase (GR) and CAT-SOD couple, it efficiently scavenges free radical species such as $\mathrm{H}_{2} \mathrm{O}_{2}$, superoxide anions and alkoxy radicals.

As a substrate for antioxidant enzymes GSHPx and glutathione transferase (GST), it protects cellular constituents from the damaging effects of ROS and peroxides formed during metabolism. Decreased GSH levels in Adr intoxicated rats may be due to its enhanced utilization for augmenting the activities of GSH-Px and GST.

Glutathione levels depleted by Adr-induced damage were significantly $(p<0.001)$ elevated by BC (300 and $450 \mathrm{mg} / \mathrm{kg}$ ) and vitamin $\mathrm{E}$ pre-treatment. It may be understood that increased levels of GSH could be because of its enhanced synthesis or due to improved GR activity in presence of $\mathrm{BC}$.

Adr treatment to Wister rats causes significant decrease $(p<0.001)$ in SOD activity in the myocardium as compared to control. Pre-treatment with BC (300 $\mathrm{mg} / \mathrm{kg}$ and $450 \mathrm{mg} / \mathrm{kg}$ ) significantly increased the SOD activity $(p<0.001)$ as compared to Adr-treated animals. No significant increase in SOD activity was noticed at $150 \mathrm{mg} / \mathrm{kg}$ dose of BC (Table 1).

Adr-induced myocardial necrosis produced a significant depletion in activities of antioxidant enzymes such as CAT $(p<0.001)$ and GSH-Px $(p<0.001)$ compared to normal animals. BC (300 and $450 \mathrm{mg} / \mathrm{kg}$ ) and vitamin $\mathrm{E}$ pre-treatment to myocardial necrotic rats significantly restored the activities of CAT $(p<0.001)$ and GSH-Px $(p<0.001)$. BC $150 \mathrm{mg} / \mathrm{kg}$, however, could only

Table 1. Biochemical parameters in different experimental groups

\begin{tabular}{llcccccc}
\hline & \multicolumn{1}{c}{ Groups/unit } & GI & GII & GIII & GIV & GV & GVI \\
\hline Biochemical & TBARS $(\mu \mathrm{M} / \mathrm{g}$ tissue) & $570.3 \pm 5.57$ & $1243.2 \pm 4.91 \dagger$ & $1212.3 \pm 2.11$ & $958.6 \pm 6.9^{\mathrm{c}}$ & $755.8 \pm 8.0^{\mathrm{c}}$ & $654.3 \pm 12.2^{\mathrm{c}}$ \\
parameters in heart & SOD (U/mg-protein) & $1.76 \pm 0.03$ & $0.4 \pm 0.03 \dagger$ & $0.51 \pm 0.008$ & $0.71 \pm 0.01^{\mathrm{c}}$ & $1.48 \pm 0.04^{\mathrm{c}}$ & $1.55 \pm 0.04^{\mathrm{c}}$ \\
& GSHogenate & $275.5 \pm 1.60$ & $203.0 \pm 2.85 \dagger$ & $208.6 \pm 1.11$ & $247.1 \pm 1.19^{\mathrm{c}}$ & $253.5 \pm 1.23^{\mathrm{c}}$ & $255.3 \pm 1.40^{\mathrm{c}}$ \\
& CAT (U/mg-protein) & $55.15 \pm 0.99$ & $34.75 \pm 0.92 \dagger$ & $38.03 \pm 0.47$ & $46.2 \pm 1.52^{\mathrm{c}}$ & $47.78 \pm 1.22^{\mathrm{c}}$ & $51.56 \pm 0.87^{\mathrm{c}}$ \\
& GSH-PX ( $\mu$ g/g tissue) & $273.5 \pm 1.03$ & $206.89 \pm 1.06 \dagger$ & $212.9 \pm 1.92$ & $249.1 \pm 1.7^{\mathrm{c}}$ & $259.5 \pm 2.51^{\mathrm{c}}$ & $266.6 \pm 1.70^{\mathrm{c}}$ \\
& SGOT (U/I) & $205.0 \pm 1.2$ & $41.56 \pm 1.18 \dagger$ & $44.3 \pm 1.54$ & $129.4 \pm 1.06^{\mathrm{c}}$ & $196.6 \pm 1.8^{\mathrm{c}}$ & $197.6 \pm 1.84^{\mathrm{c}}$ \\
& LDH (U/I) & $203.4 \pm 1.59$ & $74.21 \pm 1.55 \dagger$ & $83.1 \pm 0.32$ & $149.1 \pm 1.64^{\mathrm{c}}$ & $181.1 \pm 2.33^{\mathrm{c}}$ & $198.7 \pm 1.65^{\mathrm{c}}$ \\
Biochemical & TBARS ( $\mu \mathrm{M} / \mathrm{g}$ tissue) & $234.1 \pm 2.22$ & $432.2 \pm 3.13 \dagger$ & $411.4 \pm 1.786^{\mathrm{b}}$ & $383.6 \pm 2.87^{\mathrm{c}}$ & $332.4 \pm 2.71^{\mathrm{c}}$ & $285.6 \pm 4.58^{\mathrm{c}}$ \\
parameters in serum & SGOT (U/I) & $91.32 \pm 1.33$ & $213.32 \pm 4.89 \dagger$ & $207.54 \pm 2.87$ & $166.8 \pm 0.17^{\mathrm{c}}$ & $117.1 \pm 0.12^{\mathrm{c}}$ & $102.76 \pm 2.53^{\mathrm{c}}$ \\
& LDH (U/I) & $75.12 \pm 1.34$ & $187.85 \pm 1.05 \dagger$ & $176.21 \pm 1.68^{\mathrm{a}}$ & $107.3 \pm 1.55^{\mathrm{c}}$ & $91.77 \pm 1.34^{\mathrm{c}}$ & $85.2 \pm 1.99^{\mathrm{c}}$ \\
\hline
\end{tabular}

$\mathrm{n}=6 ;{ }^{\prime} p<0.001$ versus GI; ${ }^{a} p<0.05,{ }^{b} p<0.01,{ }^{c} p<0.001$ versus GII; Values are obtained by one way ANOVA followed by Bonferroni tests; GI: Normal saline $(0.75 \mathrm{ml} / \mathrm{animal})$, orally six days/week for four weeks; GII: Saline $(0.75 \mathrm{~mL} / \mathrm{animal})+\mathrm{Adr}(20 \mathrm{mg} / \mathrm{kg})$, single i.p. injection after four weeks; GIII: BC (150 mg/kg), orally for four weeks + Adr single i.p. injection after four weeks; GIV: BC ( $300 \mathrm{mg} / \mathrm{kg})$, orally for four weeks + Adr single i.p. injection after four weeks; GV: BC (450 mg/kg), orally for four weeks + Adr single i.p. injection after four weeks; GVI: Vitamin E (100 mg/kg), orally for four weeks +Adr single i.p. injection after four weeks. 
restore the Adr depleted activities of CAT and GSH-Px insignificantly.

SOD, CAT and GSH-Px constitute a mutually supportive enzyme system of the first line cellular defense against oxidative injury, decomposing $\mathrm{O}_{2}$ and $\mathrm{H}_{2} \mathrm{O}_{2}$ before their interaction to form the more harmful hydroxyl radical (Li et al., 1988).

In the present study, SOD activity decreased significantly in the Adr group of animals may be due to an excessive formation of superoxide anions. A decrease in SOD activity can result in the decreased removal of superoxide anions, which can be harmful to the myocardium (Sharma et al., 2001). The activities of $\mathrm{H}_{2} \mathrm{O}_{2}$ scavenging enzymes CAT and GSH-Px also decreased significantly after Adr treatment. The decline in these enzyme levels may be explained by the fact that excessive superoxide anions may inactivate SOD, thus, resulting in an inactivation of the $\mathrm{H}_{2} \mathrm{O}_{2}$ scavenging enzymes. Pretreatment with $\mathrm{BC} /$ vitamin $\mathrm{E}$ to $\mathrm{Adr}$ challenged rats heart effectively prevented the decrease in SOD, CAT and GSH-Px activities, which may be correlated directly to the scavenging of radicals by $\mathrm{BC}$ resulting in protection of these enzymes (Tosaki et al., 1994; Panda \& Naik, 2008).

Adr showed significant $(p<0.001)$ decrease in the level of cardiac marker enzymes (SGOT and LDH) in heart homogenate with a corresponding increase in their levels in the serum when compared with normal control. Increase in the activity of these enzymes in serum could be due to leakage of these enzymes from the heart as a result of free radicals induced necrosis (Peer et al.,
2008). In vitamin $\mathrm{E}$ and $\mathrm{BC}(300$ and $450 \mathrm{mg} / \mathrm{kg}$ ) treated groups significant $(p<0.001)$ increase of LDH in heart homogenate and decrease of SGOT and LDH in serum were observed.

Cardiotoxicity induced by Adr was further assessed using H\&E stain. The heart of control group showed regular cell distribution and normal myocardium morphology. Histology of the rat heart from Adr-treated animals revealed the cytoplasmic vacuole formation, mitochondrial swelling, leukocyte infiltration and myofibrillar loss, which is a typical finding in Adr-induced cardiomyopathy. Myocardial infarction was significantly reduced in animals those received $\mathrm{BC} /$ vitamin $\mathrm{E}$ treatment (Figure 1). BC (300 and $450 \mathrm{mg} / \mathrm{kg}$, p.o.) and vitamin E $(100 \mathrm{mg} / \mathrm{kg}$, p.o. $)$ maintained all biochemical and histopathological parameters near normal as compared to Adr group, indicating cardioprotective activity of BC.

\section{Conclusion}

In conclusion, $\mathrm{BC}$ showed cardioprotective effect against Adr-induced myocardial infarction and it may be due to its antioxidant effect. Therefore further studies are required to prove the potential of this plant.

\section{Acknowledgement}

Authors acknowledge to All India Council for Technical Education, New Delhi \& Himalayan Pharmacy Institute, East Sikkim for their financial support to carryout this research work (AICTE/F. No: 8023/BOR/RID/ RPS-206/2007).
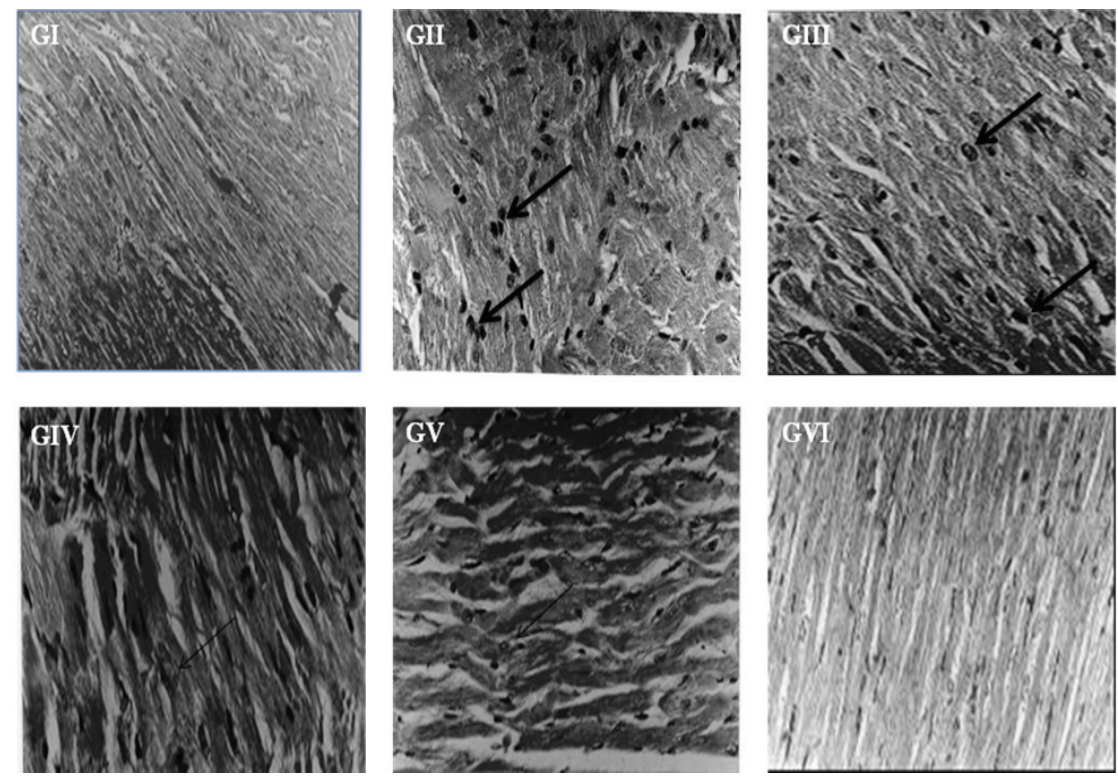

Figure 1. Effect of aqueous extract of Bombax ceiba L., Malvaceae, flowers on myocardial morphology: (GI) Control rat heart showed normal structure. (GII) Rat treated with Adr alone showed cytoplasmic vacuole formation, mitochondrial swelling, leukocyte infiltration, edema and myofibrillar loss. (GIII) BC $150 \mathrm{mg} / \mathrm{kg}+$ Adr could not relieve the damage. (GIV) BC 300 \& (GV) $450 \mathrm{mg} / \mathrm{kg}+\mathrm{Adr}$ showed a preservation of tissue histology. (GVI) Vitamin E $100 \mathrm{mg} / \mathrm{kg}+\mathrm{Adr}$ showed near normal histological characteristics. 


\section{References}

Aebi H 1984. Catalase in vitro. In: Packer L, Orlando FL (org.) Methods in enzymology. New York: Academic Press, $\mathrm{p}$ 121-126.

Bradford MM 1976. A rapid and sensitive method for the quantitation of microgram quantities of protein utilizing the principle of protein-dye binding. Anal Biochem 7: 248-254.

Buckingham J 1992. Dictionary of natural products. London: Champan and Hall scientific data division.

CPCSEA 2003. Guidelines for laboratory animal facility. Indian J Pharmacol 35: 257-274.

Doroshow JH 1991. Doxorubicin-induced cardiotoxicity. New Engl J Med 324: 843-845.

Ellman GL 1959. Tissue sulphydryl groups. Arch Biochem Biophys 82: 70-77.

Gaziano TA, Gaziano JM 2008. Epidemiology of cardiovascular disease. In: Fauci AS, Braunwald E, Kasper DL, Hauser SL, Longo DL, Jameson JL, Loscalzo J (org.) Principles of internal medicine. New York: McGraw Hill, p 1375 1379.

Hardina R, Gersl V, Klimtova I, Simunek T, Machackova J, Adamcova M 2000. Anthracycline induced cardiotoxicity. Acta Medica 43: 75-82.

Kakkar P, Das B, Viswanatham PN 1984. A modified spectrophotometric assay of super oxide dismutase. Indian J Biochem Biophys 21: 130-132.

Lenaz LN, Page JA 1976. Cardiotoxicity of adriamycin and relateld anthracyclines. Cancer Treat Rev 3: 111-120.

Li JL, Stantman FW, Lardy HA 1988. Antioxidant enzyme systems in rat liver and skeletal muscle. Arch Biochem Biophys 263: 150-160.

Meister A 1984. New aspects of glutathione biochemistry and transport selective alterations of glutathione metabolism. Nutr Rev 42: 397-400.

Naidu MUR, Vijay Kumar K, Krishna Mohan I, Sundaram C, Singh S 2002. Protective effect of Gingko biloba extract against doxorubicin-induced cardiotoxicity in mice. Indian J Exp Biol 40: 894-900.

Okhawa H, Qohishi N, Yagi K 1979. Assay of lipid peroxides in animal tissues by thiobarbituric acid reaction. Anal Biochem 95: 351-358.

Olson RD, Mushlin PS 1990. Doxorubicin cardiotoxicity: Analysis of prevailing hypothesis. Fed Am Soc Exp Biol J 4: 3076-3086.
Panda VS, Naik SR 2008. Cardioprotective activity of Ginkgo biloba phytosomes in isoproterenol-induced myocardial necrosis in rats: A biochemical and histoarchitectural evaluation. Exp Toxicol Pathol 60: 397-404.

Peer PA, Trivedi PC, Nigade PB, Ghaisas MM, Deshpande AD 2008. Cardioprotective effect of Azadirachta indica A. Juss. on isoprenaline induced myocardial infarction in rats. Int J Cardiol 126: 123-126.

Rotruck JT, Pope AL, Ganther HE, Hofeman DG, Hoeksta WG 1973. Selenium: biochemical role as a component of glutathione peroxidase. Science 179: 588-590.

Saleem R, Ahmad SI, Ahmad M, Faizi Z, Rehman S, Ali M, Faizi S 2003. Hypotensive activity and toxicology of constituents from Bombax ceiba stem bark. Biol Pharm Bull 26: 41-46.

Sharma M, Kishore K, Gupta SK, Joshi S, Arya DS 2001. Cardioprotective potential of Ocimum sanctum in isoproterenol induced myocardial infarction in rats. $\mathrm{Mol}$ Cell Biochem 225: 75-83.

Singh G, Singh AT, Abraham A, Bhat B, Mukherjee A, Verma $\mathrm{R}$, Agarwal SK, Jha S, Mukherjee R, Burman AC 2008. Protective effects of Terminalia arjuna against Doxorubicin-induced cardiotoxicity. J Ethnopharmacol 117: 123-129.

Sinha BK, Politi PM 1990. Anthracyclines. Cancer Chemother 11: 45-57.

Takacs IE, Matkovics B, Varga SI, Homolay P, Feer G, Seres T 1992. Study of the myocardial antioxidant defence in various species. Pharmacol Res 25: 177-178.

Tosaki A, Engelman DT, Pali T, Engelman RM, Droy Lefaix MT 1994. Ginkgo biloba Extract (EGb-761) improves postischemic function in isolated preconditioned working rat hearts. Coronary Artery Dis 5: 443-450.

Vieira TO, Said A, Aboutab E, Azzam M, Creczynski P, Tania B 2009. Antioxidant activity of methanolic extract of Bombax ceiba. Redox Rep 14: 41-46.

Ytrehus KT, Hegstad AC 1991. Lipid peroxidation and membrane damage of the heart. Acta Physiol Scand 324: 843-845.

\section{*Correspondence}

Sita Sharan Patel

Cardiovascular Research Division, Himalayan Pharmacy Institute Majhitar, East Sikkim, 737136 India

Tel.: +91 7869106259

Fax: +913592246462 